\title{
Insuficiência renal aguda como manifestação inicial de linfoma de Burkitt renal
}

\section{Acute renal failure as first clinical presentation of Burkitt's renal lymphoma}

José Gastão Rocha de Carvalho'; Jean Rodrigo Tafarel2; Wilson Beleski de Carvalho²; Ana Paula de Azambuja²; Elicéia Soraia Zenaro²; Rodrigo Bendlin ${ }^{3}$

\begin{tabular}{l|l}
\multicolumn{1}{c|}{ unitermos } & resumo \\
Linfoma de Burkitt & $\begin{array}{l}\text { Relatamos o caso de um jovem de } 14 \text { anos que procurou atendimento médico por edema e hiperten- } \\
\text { são, sendo insuficiência renal aguda secundária a linfoma de Burkitt renal diagnosticada após avaliação } \\
\text { laboratorial, de imagem e biópsia de massa tumoral renal. }\end{array}$
\end{tabular}

abstract

This case report is from a 14-year-old boy who had edema and hypertension due to a primary renal Burkitt's lymphoma, diagnosed through laboratory and image evaluation and kidney tumor biopsy. key words

Burkitt's lymphoma

Kidney biopsy

\section{Introdução}

O acometimento renal dos diferentes tipos de linfoma pode ocorrer devido ao efeito local direto do próprio tumor (trombose venosa, obstrução ureteral), a manifestações extra-renais dos mesmos (hiperparaproteinemia, hemólise, hipercalcemia, hiperuricemia) ou, mais raramente, ao envolvimento renal primário pelo tumor. Muitas vezes o comprometimento renal não recebe a devida ênfase. Estudos mostram que aproximadamente $30 \%-50 \%$ dos pacientes que falecem de linfoma não-Hodgkin (LNH) possuem envolvimento renal, mas em apenas $1 \%$ deles há suspeição clínica ou diagnóstico pré-morte ${ }^{(1,5,6)}$.
O envolvimento renal é mais comum nos linfomas não-Hodgkin. No entanto, o linfoma primário renal é uma forma extremamente rara de comprometimento extranodal desses tumores.

\section{Relato de caso}

Paciente masculino de 14 anos de idade, previamente hígido, foi admitido no Serviço de Emergências do Hospital de Clínicas da Universidade Federal do Paraná (UFPR) por vômitos e edema (primeiramente em membros inferiores e posteriormente em face) iniciados duas semanas antes do atendimento. Negava infecções de pele ou amigdalianas, alterações na cor ou na freqüência

1. Professor-adjunto do Departamento de Clínica Médica, disciplina de Nefrologia do Setor de Ciências da Saúde da Universidade Federal do Paraná (UFPR). 
urinária, emagrecimento, sudorese, episódios álgicos ou uso prévio de medicações.

Ao exame físico apresentava-se hipertenso $(170 / 90 \mathrm{mmHg})$, mas afebril e com o restante dos dados vitais estáveis. Destacava-se tumoração abdominal palpável em flanco direito com extensão para mesogástrico, fossa ilíaca direita e flanco esquerdo, móvel e indolor. Apresentava edema compressível e bilateral (++++/IV) em membros inferiores e discreto edema bipalpebral.

Procedeu-se à realização de exames bioquímicos e urinálise (Tabela 1), bem como a ecografia e tomografia abdominal. Evidenciou-se, pelos exames, imagem de aumento do parênquima renal bilateralmente (aproximadamente $22 \mathrm{~cm}$ de diâmetro), com contornos lobulados e densidade heterogênea. Não havia dilatação pielocalicial, linfonodomegalia retroperitoneal ou comprometimento de outras vísceras (Figuras 1A e 1B).

O paciente tinha insuficiência renal aguda na apresentação, com creatinina em $6,2 \mathrm{mg} / \mathrm{dl}$, uréia em $164 \mathrm{mg} / \mathrm{dl}$, e oligoanúria. Evoluiu com piora progressiva da função renal, náuseas e vômitos, sendo indicada hemodiálise.

Durante a investigação clínica realizou-se biópsia renal guiada por ecografia em rim direito, com obtenção de material para análise histopatológica e de imunofenotipagem. A histologia mostrava padrão em céu estrelado (Figuras $\mathbf{2 A}$ e 2B) e a análise imuno-histoquímica confirmou o diagnóstico de linfoma de Burkitt, já que os marcadores Pan-B e Ki67 foram positivos, sendo este presente em $100 \%$ das células neoplásicas. A imunofenotipagem complementou o diagnóstico mostrando $90,9 \%$ de linfócitos B, estes com

\section{Tabela 1 Exames bioquímicos e urinálise}

\begin{tabular}{|c|c|c|c|c|c|c|}
\hline & $\begin{array}{c}\text { Primeiro } \\
\text { dia }\end{array}$ & $\begin{array}{l}\text { Quarto } \\
\text { dia }\end{array}$ & D3 citorredução & D7 citorredução & $\begin{array}{l}\text { D8 citorredução e } \\
\text { D1 Hiper-CVAD }\end{array}$ & $\begin{array}{l}\text { D } 19 \text { Hiper- } \\
\text { CVAD }\end{array}$ \\
\hline VG $(\%)$ & 33,2 & 32,1 & & 28 & 25,2 & 27,7 \\
\hline $\mathrm{HB}(\mathrm{g} / \mathrm{dl})$ & 11,5 & 10,9 & & 9,7 & 8,2 & 9,4 \\
\hline Leucócitos $/ \mathrm{mm}^{3}$ & 8.500 & 8.210 & & 19.400 & 120 & 10 \\
\hline Eosinófilos $/ \mathrm{mm}^{3}$ & 680 & 246 & & 194 & 0 & 0 \\
\hline Neutrófilos $/ \mathrm{mm}^{3}$ & 5.030 & 5.254 & & 17.468 & 0 & 0 \\
\hline Linfócitos $/ \mathrm{mm}^{3}$ & 2.295 & 1.888 & & 1.552 & 120 & 10 \\
\hline Plaquetas $/ \mathrm{mm}^{3}$ & 269.000 & 307.000 & & 321.000 & 228.000 & 44.000 \\
\hline Sódio (mEq/l) & 145 & 140 & 140 & 138 & 140 & 125 \\
\hline Potássio (mEq/l) & 5,7 & 5,5 & 6,4 & 4,9 & 5,6 & 3,4 \\
\hline Creatinina $(\mathrm{mEq} / \mathrm{l})$ & 8,7 & 10,5 & 5,7 & 5,5 & 4,2 & 6 \\
\hline Uréia (mg/dl) & 189 & 220 & 192 & 150 & 138 & 193 \\
\hline $\begin{array}{l}\text { Clearance de } \\
\text { creatinina ( }(/ \mathrm{min})\end{array}$ & & 6,5 & & & & \\
\hline Diurese (ml) & 200 & 200 & 1.000 & & & \\
\hline \multicolumn{7}{|l|}{ Urina } \\
\hline Densidade & 1,01 & & & & & \\
\hline Proteína & + & & & & & \\
\hline $\mathrm{PH}$ & 6 & & & & & \\
\hline Leucócitos/ml & 20.000 & & & & & \\
\hline Eritrócitos/ml & 19.000 & & & & & \\
\hline Cilindros & Ausentes & & & & & \\
\hline Proteína 24 horas $(\mathrm{g} / \mathrm{l})$ & & 0,47 & & & & \\
\hline Volume 24 horas (ml) & & 1.100 & & & & \\
\hline
\end{tabular}




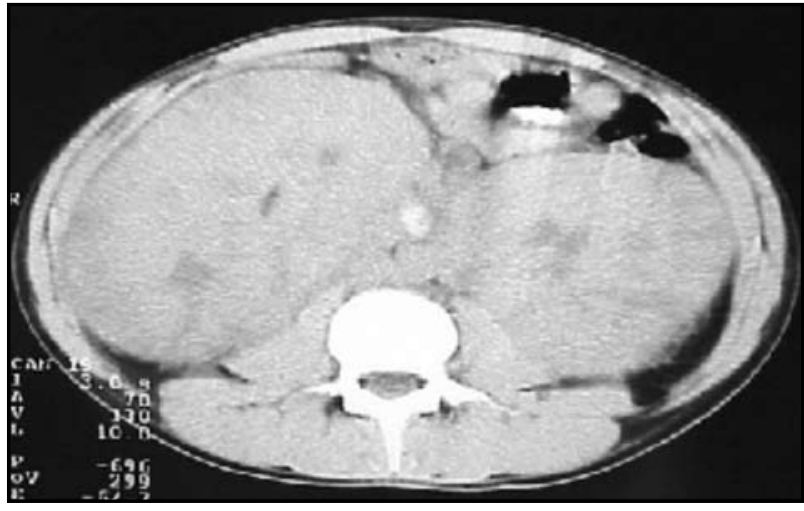

Figura 1A - Observa-se aumento de parênquima renal bilateral, com contornos lobulados



Figura 1B - Não há linfonodomegalia retroperitoneal ou comprometimento de outras vísceras

positividade para CD10-/+, CD19+/++, CD20+/++ heterogêneo, CD45++/+++ e cadeias leves lambda; e negatividade para CD3, CD4, CD5, CD8, CD13, CD34 e cadeia leve kappa. Esse conjunto de exames permite concluir tratar-se de linfoma Burkitt primário renal|(3).

Para avaliação completa do caso realizaram-se aspirado e biópsia de medula óssea, que revelaram medula óssea hipocelular para a idade, com ausência de células clonais neoplásicas. A tomografia de tórax foi normal, sem adenomegalias ou comprometimento de outros órgãos intratorácicos. O diagnóstico final foi linfoma de Burkitt renal estadiamento clínico (EC) IV.

O paciente iniciou quimioterapia com prednisona e ciclofosfamida com objetivo de citorredução. Houve grande redução da massa tumoral, porém lise tumoral intensa apresentou-se como intercorrência, com ácido úrico $16 \mathrm{mg} / \mathrm{dl}$, fósforo inorgânico $10 \mathrm{mg} / \mathrm{dl}$ e hipocalcemia de $5 \mathrm{mg} / \mathrm{dl}$. O quadro foi manejado com intensificação da hemodiálise e alopurinol. O controle tomográfico após esse esquema mostrou redução de $50 \%$ da massa tumoral. O seguimento

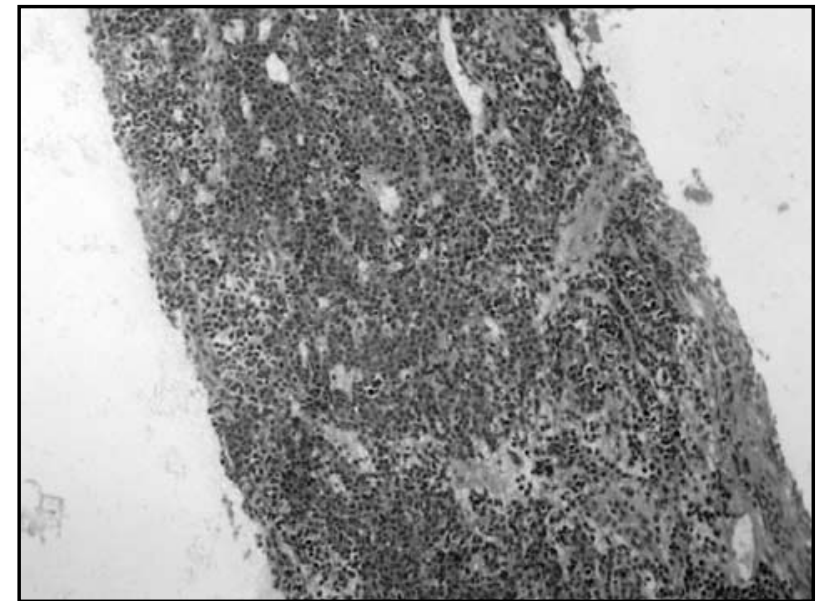

Figura $\mathbf{2 A}$ - Amostra de tecido composta quase que inteiramente por células neoplásicas

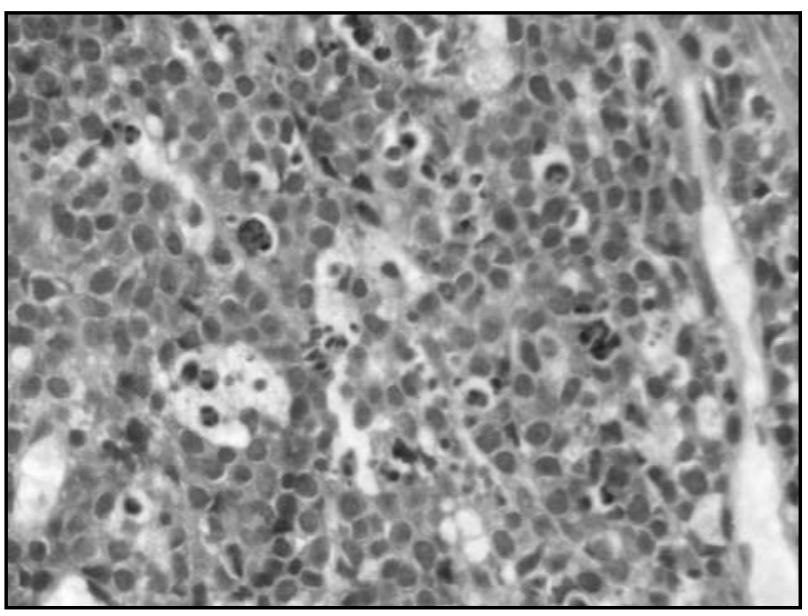

Figura 2B - Notam-se alguns macrófagos contendo debris celulares no citoplasma das células neoplásicas, caracterizando o aspecto em céu estrelado

do tratamento foi realizado com esquema ciclofosfamida hiper-fracionada, vincristina, doxorrubicina, dexametasona (hiper-CVAD) ${ }^{(5)}$, pelo possível efeito deletério que as altas doses de metotrexate poderiam trazer à função renal do paciente com o esquema do Cancer and Leukemia Group B (CALGB [primeira opção de tratamento]).

A resposta inicial foi satisfatória, porém o paciente apresentou prolongado tempo de neutropenia severa (menos de 100 neutrófilos por mais de 15 dias), caracterizando toxicidade hematológica grau IV. Apresentou ainda mucosite grau III e candidíase de orofaringe e esofágica. Evoluiu com infecção pulmonar e sepse, necessitando de suporte hemodinâmico e ventilatório, antibioticoterapia de amplo espectro e antifúngicos. Evoluiu com sepse severa, falência de múltiplos órgãos e óbito 25 dias após o início do tratamento. 


\section{Discussão}

A prevalência de $\mathrm{LNH}$ primário renal é menor que $0,5 \%$, sendo este geralmente um linfoma de células $B$ de alto grau ou de grau intermediário e crescimento rápido ${ }^{(5,6)}$. Em revisão recente feita por $\mathrm{Da}^{\prime}$ as et al., apenas 65 casos de linfoma primário renal haviam sido relatados até o ano 2000 , sendo que destes, $43 \%$ eram bilaterais ${ }^{(1)}$. Analisandose apenas linfomas de Burkitt primários de rim, o primeiro caso foi relatado em 1997 por Sienawska et al. ${ }^{(7)}$.

Como os rins não possuem tecido linfóide, muitos autores duvidam da real existência desse tipo de tumor. Puente Daunay postula que processos inflamatórios preexistentes recrutam células linfóides para o parênquima renal. Quando as células chegam a esse destino, eventos oncogênicos começam a atuar( ${ }^{(2)}$. Outros autores acreditam que, devido à alta vascularização linfática da cápsula renal, seria possível que células tumorais colonizassem o parênquima renal( ${ }^{(6)}$.

Entre as séries de pacientes publicadas na literatura há prevalência de homens com média etária de 48 anos ao diagnóstico, sendo que na maioria dos casos a creatinina sérica ao diagnóstico era superior a $3,5 \mathrm{mg} / \mathrm{dl}^{(5)}$.

O principal sintoma apresentado pelos pacientes é a dor em flanco, o que torna o diagnóstico clínico inicial extremamente difícil pela inespecificidade da queixa ${ }^{(6)}$. LNH primário renal pode também se manifestar com hematúria, emagrecimento, fraqueza, hipertensão arterial e massa abdominal palpável $(5,7)$. A ocorrência de insuficiência renal em pacientes com linfoma pode surgir devido ao comprometimento direto do sistema urinário (obstrução ureteral ou dos vasos renais, infiltração do parênquima renal, ou ruptura renal ou ureteral), a alterações endócrino-metabólicas (hipercalemia, secreção de PTH-símile e paraproteinemias) ou por efeito do tratamento (nefrite radioativa e síndrome de lise tumoral) ${ }^{(5)}$.

O diagnóstico definitivo de linfoma renal deve preencher os seguintes critérios ${ }^{(1,5)}$, todos presentes no nosso paciente:
1. aumento renal sem evidências de obstrução e sem envolvimento nodal ou de outros órgãos;

2. diagnóstico feito pela biópsia renal;

3. insuficiência renal como apresentação inicial;

4. ausência de outras causas para insuficiência renal;

5. rápida melhora da função renal após radioterapia ou quimioterapia sistêmica.

A tomografia computadorizada mostrou-se o exame de maiores sensibilidade e especificidade quando comparado à ultra-sonografia ${ }^{(5)}$. Sempre se deve pensar em envolvimento renal por linfoma quando múltiplas áreas homogêneas e hipodensas (com baixa atenuação pelo contraste) aparecerem em região perirrenal ou no parênquima renal(5). A ressonância nuclear magnética mostrou-se útil, especialmente naqueles doentes com contra-indicação ao uso do contraste iodado ${ }^{(5)}$. Apesar dos meios de imagem fornecerem indícios do diagnóstico, este só é obtido de forma inequívoca através da biopsia renal.

Entre as formas de tratamento há descrições de cirurgias, combinações de quimioterapias e radioterapia ${ }^{(6)}$. $\mathrm{O}$ tratamento convencional dos linfomas de Burkitt consiste em quimioterapia de alta intensidade e curta duração, com o objetivo de atingir as células de crescimento rápido com período de duplicação menor que 24 horas. Drogas como ciclofosfamida, corticóide, vincristina, metotrexato, doxorrubicina e citarabina são ativas em linfoma de Burkitt. Os protocolos mais estudados, como hiper-CVAD e CALGB, têm mostrado cerca de $80 \%$ de remissão completa e $50 \%$ de sobrevida livre de doença em quatro anos ${ }^{(4,8)}$. Entretanto, o uso de metotrexato e citarabina é associado à toxicidade renal. Além disso, a lise tumoral induzida pela quimioterapia pode predispor a precipitação de cristais de ácido úrico nos túbulos renais e piora da lesão renal. Assim, em todos os pacientes a função renal deve ser monitorada, e em pacientes com insuficiência renal há mais dificuldade em usar essas drogas, uma vez que a toxicidade pode ser maior.

\section{Referências}

I. DA'AS, N.; POLLIACK, A.; COHEN, Y. et al. Kidney involvement and renal manifestations in non-Hodgkin's lymphoma and lymphocytic leukemia: a retrospective study in 700 patients. Eur J Haematol, v. 67, p. 158-64, 2001.

2. DUANAY, P. N. et al. Linfosarcoma y linfosarcomatosis de los riñones: part II. Rev Med Trop Parasitol Bacterial Clin Lab, v. 6. p. 213,1940
3. HARRIS, N. L. et al. A revised European-American classification of lymphoid neoplasms: a proposal from the international lymphoma study group. Blood, v. 84, p. I 361-92, 1994

4. LEE, E. J. et al. Brief duration high-intensity chemotherapy for patients with small noncleaved-cell limphoma or FAB L3 acute lymphocytic leukemia: results of Cancer and Leukemia Group B Study 925।.J Clin Oncol, v. 19, p. 40।4-22, 200।. 
5. MALBRAIN, M. L. N.; LAMBRECHT, G. L.Y.; DAELEMANS, R. et al. Acute renal failure due to bilateral lymphomatous infiltrates. Primary extranodal non-Hodgkin's lymphoma (p-EN-NHL) of the kidneys: does it really exist? Clinical Nephrology, v. 42 n. 3, p. 163-9, 1994.

6. OKUNO, S. H.; HOYER, J.D.; RISTOW, K. et al. Primary renal nonHodgkin's lymphoma. Cancer, v. 75, n. 9, p. 2258-6I, 1995.
7. SIENIAWSKA, M.; BIALASIK, D.; JEDRZEJOWSKI,A. et al. Bilateral primary renal Burkitt lymphoma in a child presenting with acute renal failure. Nephrol Dial Transplant, v. I2, p. 1490-2, 1997.

8. THOMAS, D. A.; CORTES, J.; O'BRIEN S. et al. Hyper CVAD Program in Burkitt's type adult acute lymphoblastic leukemia. J Clin Oncol, v. 17, p. 2461-70, 1999. 